\title{
An integrative therapy for paraplegia dog with ehrlichiosis $\uparrow$
}

\author{
Frizky Amelia ${ }^{1,5, *}$, Danny Umbu T.H. ${ }^{2}$, Erly R. Adistya ${ }^{2}$, Rr. Soesatyoratih ${ }^{2,3}$, Leni Maylina ${ }^{4}$, \\ Nindya D. Utami ${ }^{1}$, Tatang Cahyono ${ }^{5}$, Deni Noviana ${ }^{2,3}$ \\ ${ }^{1}$ Animal Biomedical Science, Graduate School of IPB University, Bogor \\ ${ }^{2}$ Veterinary Teaching Hospital, Faculty of Veterinary Medicine, IPB University, Bogor \\ ${ }^{3}$ Division of Surgery and Radiology, Faculty of Veterinary Medicine, IPB University, Bogor \\ ${ }^{4}$ Division of Internal Medicine, Faculty of Veterinary Medicine, IPB University, Bogor \\ ${ }^{5}$ Indonesian Association of Traditional Chinese Veterinary Medicine (IATCVM), Jakarta
}

\begin{abstract}
An eight-months-old male Golden Retriever was referred to Veterinary Teaching Hospitalof IPB University with clinical signs of non-ambulatory paraplegia, tail paralysis, urinary and faecal incontinence, pale mucosa, and loss of sensory and motoric responses on both pelvic limbs. The hematology examination showed thrombocytopenia $\left(125 \times 10^{3} / \mu \mathrm{L}\right), \mathrm{mo}-$ nocytopenia $\left(0.09 \times 10^{3} / \mu \mathrm{L}\right)$, and no significant decreased of hematocrit $(36.88 \%)$. Rapid diagnostic test and blood smears were positive for Ehrlichiacanis infection. Abdominalsonogram showed splenomegaly and hepatomegaly with hepatic vessels dilatation. An integrative therapy was done using medications (vitamin B-complex, cyproheptadine, methylprednisolone, doxycycline, and Fundamin $\mathrm{E}^{\circledR}$ ), herbal (Gui Pi Tang ${ }^{\circledR}$ and Fu Fang Ejiao Jiang ${ }^{\circledR}$ ), acupuncture, micro-radar, and Tuina massage. The dog was able to walk and run after $10^{\text {th }}$ session of the intensivetreatment then discharged from the hospital after two months. One week after, the dog started dragging his toe. A customized shoe then made to prevent furtherinjury to the affected limb. The acupuncture was continued once a week for the following two months. The dog is still able to walk and run at his last visit 5 months later. This shows that an integrative therapycan give a good performance in recovering ambulation of paraplegia dog with ehrlichiosis.
\end{abstract}

Keywords:

acupuncture, conventional medicine, eastern medicine, ehrlichiosis, paraplegia.

\section{-INTRODUCTION}

History and anamnese: An eight-months-old male Golden Retriever, weighing $25 \mathrm{~kg}$, presented for pelvic limbs and tail paralysis. The owner reported that the dog suddenly cannot walk after playing with his fellow dogs at home and suspected lumbar trauma. The dog has not received any treatment for 2 weeks.

Clinical findings: The physical examination showed a general weakness, pale mucous, stiffness at both thoracic limbs, pelvic limbs and tail paralysis without signs of pain at the palpation along the vertebrae (Figure 1a). The heart rate was 122 beats per minute, respiration rate of 44 times per minute, and body temperature of $39^{\circ} \mathrm{C}$. Several wounds found on his rear due to dragged pelvic limbs. Severe skin irritation on his abdominal and inguinalarea was marked due to urinary and faecal incontinence. Neurological examination disclosed an alert mental status and nonambulatory paraplegia with mild muscle atrophy at both pelvic limbs. Proprioceptive deficits were detected at all four limbs, but more severe in pelvic limbs. Patellar, withdrawal, and anal reflexes were decreased.

\section{- MATERIALAND METHODS}

Diagnostic tests: No abnormalities found in the radiograph and blood chemistry examinations. The hematology examination showed thrombocytopenia $\left(125 \times 10^{3} / \mu \mathrm{L}\right)$, monocytopenia $\left(0.09 \times 10^{3} / \mu \mathrm{L}\right)$, and no significant decreased of hematocrit $(36.88 \%)$. The blood smears and rapid tests were positive for Ehrlichia canis infection. Hepatomegaly and splenomegaly were significantly observed in dog's sonogram (Figure S1).

Differential diagnosis and prognosis: The diagnosis based on conventional medicinewas non-ambulatory paraplegia and ehrlichiosis. In Traditional Chinese Veterinary Medicine (TCVM), this condition called local Qi and Blood stagnation at lumbar area leading to KID yin deficiency with blood deficiency. The prognosis was good due to young age and positive response towards the integrative therapy.
Received: 12-10-2019 | Revised:05-11-2019 | Accepted:11-11-2019

(C) 2019 CC-BY-SA. This is an Open Access article that is distributed under the terms of Creative Commons Attribution ShareAlike 4.0 International License (https://creativecommons.org/licenses/by-sa/4.0/). 
Treatments: The dog was hospitalized and received vitamin B-complex (Neurobion ${ }^{\circledR} 200 \mathrm{mcg} / \mathrm{kg}$ once per day PO) and cyproheptadine (Pronicy ${ }^{\circledR} 2 \mathrm{mg} / \mathrm{kg}$ twice per day PO) for a week. Then the medication changed into methylprednisolone $(2 \mathrm{mg} / \mathrm{kg}$ twice per day PO), multivitamin (Fundamin $\mathrm{E}^{\circledR}$ one tablet daily), doxycycline $(5 \mathrm{mg} / \mathrm{kg}$ twice per day PO), and herbal Fu Fang Ejiao Jiang $^{\circledR}$ (20mL per day PO) for 2 weeks. Gui Pi Tang ${ }^{\circledR}$ one tablet per day PO then used to replace Fu Fang Ejiao Jiang ${ }^{\circledR}$ for the following one month. Acupuncture, micro-radar, and Tuina massagewere delivered together, three times per week, for the first two months. Then it decreased into once per week for another two months after he discharged from the hospital. There were 40 acupoints chosen for this case, but one session of acupuncture only used up to 15-20 acupointsbased on the patient's condition at that very moment of therapy (See Table S2.1 and Table S2.2 for the list of acupoints and herbal functions).

\section{-RESULTS AND DISCUSSION}

Results: The recovery process of integrative therapy can be seen in Figure 1. (b-f). The dog finally can stand, walk, and run on his own on $10^{\text {th }}$ session and was discharged after 2 months (16 sessions of therapy). Then he came back one week later dragging his right pelvic limb. The skin around the paw was injured due to the friction against the ground. A customized shoe then designed for his right pelvic limb. The dog started wearing the customized shoe in January 2019 and showed a good recovery.

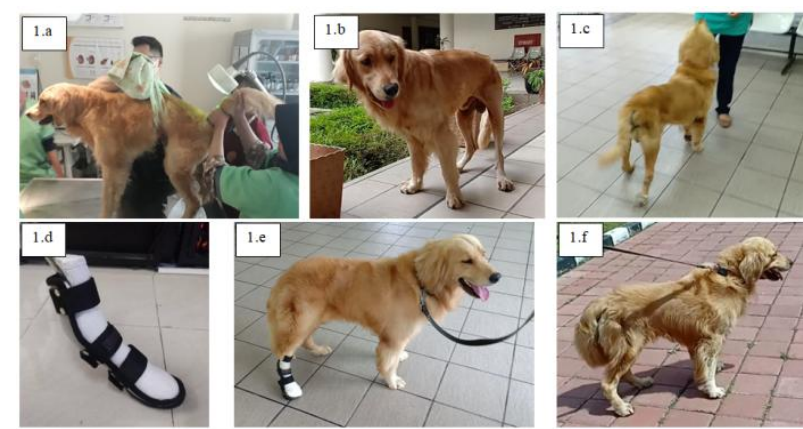

Figure 1 The recovery process of the dog: (a) first visit in July 2018, (b)after $10^{\text {th }}$ acupuncture session, (c) dragging toe, (d) the customized shoe, (e) patient wore the customized shoe to prevent him from dragging the toe, (f) last visit in April 2019.

Discussion: Paraplegia can be defined as a complete loss of voluntary motor function in the pelvic limbs (Kornegay 1991). The differential diagnosis of paraplegia are acute intervertebral disk herniation, spinal trauma, and fibrocartilaginous embolic myelopathy (Casimiro da Costa 2009). The differential diagnosis can be confirmed by using myelography, computed tomography (CT), or magnetic resonance imaging (MRI) (Jeffery et al. 2016). In this case, the dog's conditionwas getting worse due to E. canis infection. Ehrlichiosis is one of the most important tickborne zoonoses that affect dogs (Freire et al. 2009). Some neurological signs associated with ehrlichiosis are ataxia, seizures, paraparesis or tetraparesis with upper or lower motor-neuron deficits, stupor, vestibular disease, and back or neck pain (Freire et al. 2009). We used the acupuncture as the main therapy for the dog. Acupuncture has the ability to reduce the pain due to its analgesic and antiinflammatory effects and has been clinically proved to help recover ambulation in paralysis animals (Xie \& Wedemeyer 2012). Meanwhile, the customized shoe was made to correct and conditioning the 'dragging toe' limb into a normal posture and gait as well as protect the nail and skin from the damage of being dragged along the ground.

\section{- CONCLUSION}

The combination of western (conventional) and eastern (Chinese) medicine, can be used to give greater results in a shorter amount of time in treating paraplegia dog with ehrlichiosis.

\section{-ASSOCIATED CONTENT}

\section{Supporting Information}

$\dagger$ The sonogram, list of acupoints and herbal functions were submitted in PDF form as supporting information.

\section{-AUTHOR INFORMATION}

\section{Corresponding Author}

*FA: frizkyamelia@hotmail.com

Graduate School of IPB University

Jl. Raya Dramaga, Kampus IPB Dramaga, Bogor

Jawa Barat - Indonesia 16680

\section{-ACKNOWLEDGMENT}

The authors would like tothank Dr. Warangkhana Phanwanich and her team at the iVET Hospital and PETANEER - Thailand for their insight and help during the customized shoe's making process and its evaluation.

\section{-REFERENCES}

Casimiro da Costa R. 2009. Acute paraplegia-diagnosis and treatment. World Small Animal Veterinary Association (WSAVA) World Congress Proceedings 2009. https://www.vin.com/doc/?id=4252715.

Freire MN,Azevedo TS, Cunha MO, Guerra EFC, Rocha AAF, Moura SB, Peneluc T, Cerqueira RB. 2009. Canine ehrlichiosis: Clinical, hematological and serological investigation of 100 dogs. World Small Animal Veterinary Association (WSAVA) World Congress Proceedings 2009. https://www.vin.com/apputil/content/ defaultadv1. aspx id=4252820\&pid=11290.

Jeffery ND, Barker AK, Hu HZ, Alcott CJ, Kraus KH, Scanlin EM, Granger N, Levine JM. 2016. Factors associated with recovery from paraplegia in dogs with loss of pain perception in the pelvic limbs following intervertebral disk herniation. Journal of the American Veterinary Medical Association. 248(4):386-394.

Kornegay JN. 1991. Paraparesis (paraplegia), tetraparesis (tetraplegia), urinary/fecal incontinence. Spinal cord diseases. Problems in veterinary medicine.3(3):363-377.

Xie H, Wedemeyer L. 2012. The validity of acupuncture in veterinary medicine. American Journal of Traditional Chinese Veterinary Medicine.7 (1): 35-43. 


\title{
SUPPORTING INFORMATION
}

\section{An integrative therapy for paraplegia dog with ehrlichiosis}

\section{Frizky Amelia ${ }^{1,5}$, , Danny Umbu TH ${ }^{2}$, Erly R. Adistya ${ }^{2}$, RR Soesatyoratih ${ }^{2,3}$, Leni Maylina ${ }^{4}$, Nindya D. Utami ${ }^{1}$, Tatang Cahyono ${ }^{5}$, Deni Noviana ${ }^{2,3}$}

\author{
${ }^{1}$ Animal Biomedical Science, Graduate School of IPB University, Bogor \\ ${ }^{2}$ Veterinary Teaching Hospital, Faculty of Veterinary Medicine, IPB University, Bogor \\ ${ }^{3}$ Division of Surgery and Radiology, Faculty of Veterinary Medicine, IPB University, Bogor \\ ${ }^{4}$ Division of Internal Medicine, Faculty of Veterinary Medicine, IPB University, Bogor \\ ${ }^{5}$ Indonesian Association of Traditional Chinese Veterinary Medicine (IATCVM), Jakarta
}

$\dagger$ Electronic Supplementary Information (ESI) available.

See DOI: http://dx.doi.org/10.29244/avl.3.4.65-66 
Electronic Supplementary Material (ESI) for ARSHI Veterinary Letters.

This journal is (C) Fakultas Kedokteran Hewan IPB - ARSHI (Asosiasi Rumah Sakit Hewan Indonesia) 2019

\section{S 1. Sonogram of the dog}

Figure S1 showed the the sonogram of the patient. Hepatomegaly and splenomegaly were significantly observed as a concequnce and also an indicator of blood parasite infection. Vessel dilatation can also be seen in both liver and spleen.
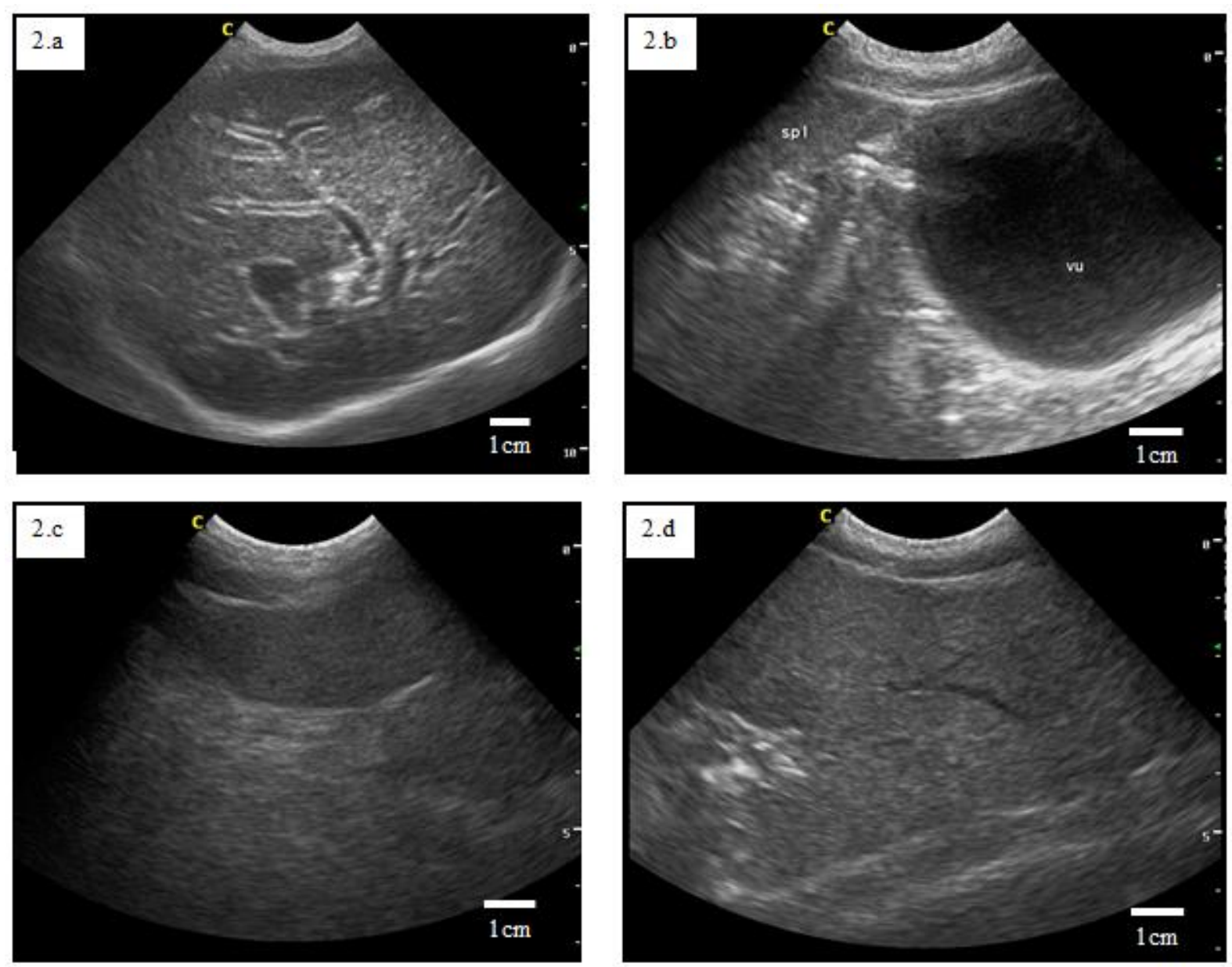

Figure S1. The sonogram of the dog: (a) hepatomegaly with hepatic vessels dilatation, and (b,c,d) splenomegaly. 
Electronic Supplementary Material (ESI) for ARSHI Veterinary Letters.

This journal is (C) Fakultas Kedokteran Hewan IPB - ARSHI (Asosiasi Rumah Sakit Hewan Indonesia) 2019

\section{S2. List of acupoints and its function}

Table S2.1 showed the acupoints chosen and used in this case. There were 40 acupoints chosen, but in one session of therapy we only used about 15 to 20 acupoints, based on the patient's condition at that very moment. The clinical indication and function of each acupoints can also be seen in Table S2.1.

Table S2.1. List of acupoints and its function

\begin{tabular}{|c|c|c|}
\hline No & Acupoint & Clinical Indication (s) or Function (s) \\
\hline 1 & Bai-hui & Diarrhea, constipation, IVDD, paresis/paralysis of pelvic limb \\
\hline 2 & Hua-tuo-jia-ji & IVDD, relieve back pain \\
\hline 3 & LIV-3 & Yuan point, remove $Q i$ stagnation and pain, paralysis of pelvic limbs \\
\hline 4 & LIV-8 & Genital pruritis, urinary incontinence \\
\hline 5 & BL-11 & Influential point for bone, IVDD, relieve back pain \\
\hline 6 & BL-17 & Back $s h u$ point for diaphragm, influential point for blood, blood/Yin deficiency \\
\hline 7 & BL-18 & Back shu point for liver, hepatic disease, relieve back pain \\
\hline 8 & BL-20 & Backshu point for spleen, support blood regulation, relieve back pain \\
\hline 9 & BL-23 & $\begin{array}{l}\text { Backshu point for kidney, support bone recovery, KID Yin /Qi deficiency, urinary } \\
\text { incontinence }\end{array}$ \\
\hline 10 & BL-24 & Qi deficiency, relieve abdominal and back pain \\
\hline 11 & BL-25 & Backshu point for large intestine, support bowel movement, relieve back pain \\
\hline 12 & BL-26 & Source $Q i$ associate, urinary incontinence, relieve back pain \\
\hline 13 & BL-28 & Backshu point for bladder, urinary incontinence, relieve lumbo-sacral pain \\
\hline 14 & BL-36 & Relieve back pain, paralysis of pelvic limb \\
\hline 15 & BL-39 & Urinary dribbling, relieve back pain and muscle spasms of pelvic limbs \\
\hline 16 & BL-40 & Master point for caudal back/hip, hip and back problem, relieve lumbar pain \\
\hline 17 & BL-54 & $\begin{array}{l}\text { Master point for pelvic limbs, paresis/paralysis of pelvic limbs, hip problem, perianal } \\
\text { problem, relieve lumbar pain }\end{array}$ \\
\hline 18 & BL-60 & Relieve back pain, cervical stiffness \\
\hline 19 & ST-25 & Constipation, diarrhea, relieve abdominal pain \\
\hline 20 & ST-35a & Pelvic limb weakness \\
\hline 21 & ST-35b & Pelvic limb weakness \\
\hline 22 & ST-36 & Master point for GI tract and abdomen, Improve Wei-Qi (general tonic) \\
\hline 23 & ST-41 & Paresis/paralysis of pelvic limbs \\
\hline 24 & SP-3 & Constipation, diarrhea, relieve abdominal pain \\
\hline 25 & SP-4 & Luo connecting point to stomach, confluent point to Chong channel \\
\hline 26 & SP-6 & Master point for caudal abdomen and urogenital system, Yin/blood deficiency \\
\hline 27 & SP-9 & Yin deficiency, skin itching \\
\hline 28 & SP-10 & Blood deficiency, blood stagnation, skin itching, paresis or paralysis of pelvic limbs \\
\hline 29 & GB-29 & Hip joint problem, paralysis of pelvic limb \\
\hline 30 & GB-30 & Hip joint problem, paralysis of pelvic limb \\
\hline 31 & GB-31 & Skin itching, paralysis of pevic limb, rear foot problem \\
\hline 32 & GB-34 & Influential point for tendon ligament \\
\hline 33 & GB-39 & $\begin{array}{l}\text { Influential point for marrow/CNS, cervical stiffness, paresis/paralysis of pelvic limbs, anal } \\
\text { problem }\end{array}$ \\
\hline 34 & LI-10 & Immune regulation, general tonic, skin itching, thoracic and pelvic limb weakness \\
\hline
\end{tabular}


Electronic Supplementary Material (ESI) for ARSHI Veterinary Letters.

This journal is (C) Fakultas Kedokteran Hewan IPB - ARSHI (Asosiasi Rumah Sakit Hewan Indonesia) 2019

\begin{tabular}{|c|c|l|}
35 & LU-9 & Influential point for blood vessels \\
\hline 36 & HT-8 & Urinary incontinence, gential itching, pain in the feet \\
\hline 37 & GV-20 & Calming point, headache \\
\hline 38 & CV-6 & KID Qi/Yangronic, loss of body weight, diarrhea \\
\hline 39 & KID-3 & Kidney source point, relieve back pain, dysuria \\
\hline 40 & Wei-jian & Tail paralysis, pelvic limb weakness \\
\hline
\end{tabular}

$\begin{array}{ll}\text { Abbreviations } \\ \text { LIV } & \text { Liver } \\ \text { BL } & \text { Bladder } \\ \text { ST } & \text { Stomach } \\ \text { SP } & \text { Spleen } \\ \text { GB } & \text { Gall bladder } \\ \text { LI } & \text { Large Intestine } \\ \text { LU } & \text { Lung } \\ \text { HT } & \text { Heart } \\ \text { GV } & \text { Governing vessel } \\ \text { CV } & \text { Conception vessel } \\ \text { KID } & \text { Kidney }\end{array}$

Tabel S2.2 listed the herbal chosen and used in this case. We only used two herbals, the $F u$ Fang Ejiao Jiang and Gui Pi Tang. Both herbals works to increasing the blood performance and also supporting the liver and spleen functions.

Table S2.2. List of herbal and its function

\begin{tabular}{|c|l|l|}
\hline No & \multicolumn{1}{|c|}{ Herbal } & \multicolumn{1}{c|}{ Clinical Indication (s) or Function (s) } \\
\hline 1 & Fu Fang Ejiao Jiang & Thrombocytopenia, blood deficiency \\
\hline 2 & Gui Pi Tang & Thrombocytopenia, blood/Qi deficiency, support spleen function \\
\hline
\end{tabular}

